\title{
Thinking of the Comprehensive Experimental Curriculum Construction based on the pattern of OBE
}

\author{
Guan qiang Ruan \\ Automotive School \\ Shanghai Dianji University \\ Shanghai, China \\ ruangq@sdju.edu.cn
}

\author{
Jin run Cheng \\ Automotive School \\ Shanghai Dianji University \\ Shanghai, China \\ jerrychan1209@163.com
}

\begin{abstract}
The content of comprehensive experimental curriculum is complex, meanwhile there is lack of effective method to evaluate student learning outcomes in the teaching process, and it has certain difficulty to realize the teaching goal of comprehensive experiment. This paper has introduced the OBE's education idea, driven by the learning outcome in the reform of teaching contents, to further improve the quality of teaching and talent training.
\end{abstract}

Keywords-OBE education mode; Comprehensive experiment; Curriculum construction

\section{OVERVIEW OF THE RESEARCH ON OBE EDUCATION MODE}

The education mode based on the learning outcomes (outcomes-based education, OBE) was initially originated from elementary education reform in western countries in the 1990s. In OBE education mode, teachers need to have a clear understanding of the abilities students should have to complete their studies, and then design the entire teaching activities including teaching plans, teaching outline and evaluation mode, etc., to ensure the achievement of teaching goal. In this mode, compared with the traditional teaching activities driven by teaching content, this is a kind of new education mode driven by learning outcomes [1]. The OBE mode emphasizes the driving force based on the students' learning outcomes, and then reversely designs teaching activities and evaluation standard to facilitate the study of students. The OBE education idea could better promote teachers to optimize teaching link and content, renovate teaching methods, emphasis on students learning effect evaluation, and then improve the quality of teaching. Based on vehicle engineering comprehensive experimental curriculum, this paper had introduced the OBE education idea, and explored a new effective way to construct the comprehensive experiment curriculum [2].

\section{THE CHARACTERISTICS AND CURRENT SITUATION} ANALYSIS OF COMPREHENSIVE EXPERIMENT CURRICULUM

The vehicle engineering comprehensive experiment curriculum is one of the professional compulsory courses of vehicle engineering, and also an important major curriculum. This curriculum is arranged on first semester of senior year, basically, all the curriculums would be completed in this semester. This comprehensive experiment is the summary and practical verification of the four-year study. In the traditional experimental teaching mode, experimental verification is the major way of knowledge imparting, mainly of the experimental purpose, experimental equipment, experimental steps, experiment data, results analysis and experimental summary, etc. Because of the lack of effective evaluating method, and the operational complex of comprehensive experimental curriculum, students are difficult to understand relevant concepts and principles in the study process. The phenomenon of deviation of knowledge imparting from teaching results, tends to the teaching goal unachievable. There are following problems mainly in traditional experimental teaching.

(1)The traditional teaching methods emphasized the experimental process orientation, and demanded students carry out experiment according to the established plan, time, and schedule, while neglecting the fundamental goal of "learning outcomes".

(2)The traditional experiment teaching methods emphasized the correctness of experiment results, teachers focus on the results of the experiment, and students focus on the collection of experimental data. There is lack of cultivating the student's ability such as reasoning, evaluating and other aspects in teaching mode.

(3)The traditional methods of teaching emphasized that the teachers are the center, and students complete experimental task according to the demands of teachers. This learning form is single, it needs introducing a team-cooperating way to improve the learning efficiency of students from all directions. In order to adapt to the demands of engineering education in our country, combining with demands and characteristics of applied undergraduate talents cultivation in Shanghai Dianji University, the OBE education idea is introduced into the construction of comprehensive experiment curriculum. It is learning outcomes-oriented and students-centered, to carry out the course teaching reform and exploration based on the learning outcomes from teaching goal, teaching content, teaching means, student evaluation etc. 


\section{THE CONSTRUCTION OF COMPREHENSIVE EXPERIMENTAL CURRICULUM IN OBE EDUCATION MODE}

OBE education mode is students-centered and learning outcomes-oriented. This kind of teaching mode is based on teaching activities that what students can gain and what skill students can master through learning, to build learning outcomes evaluating mode, while needing teachers guiding students to learn independently, paying attention to the development of students' individuality, cultivating students' autonomous learning enthusiasm, and improving teaching efficiency.

\section{A. Learning-outcomes orientation, optimizing the teaching content, establishing hierarchical teaching mode}

In the OBE education idea, the teacher should take students' learning outcomes as the goal orientation, to optimize the comprehensive experiment teaching content, and to effectively evaluate students' learning in each phase [3].

1) The basic concept learning of experimental data According

to the concept of OBE, teachers need to clear the demands of learning outcomes in this phase: master the basic concept of commonly-used experimental data, understand why to test these data, the impact of these data on the performance of the car. Especially it should be explained that there is contradiction between the multiple experimental data. The vehicle overall performance, should taking these data into account, it cannot be biased, otherwise it will lead to poor performance in some aspect.

2) The optimization of experimental data collecting process

In the traditional teaching of operation, due to various reasons, teachers take little or no optimization in the experimental data collecting process. It may go well when collecting data, but students are hard to accept, the teaching effect is poor. In the process of data collection, a variety of forms such as asking questions, group discussions, writing data collection report can be adopted to stimulate students' interest in learning, to improve the quality of teaching.

\section{3) The analysis, optimization, contrast of data}

Comprehensive experiment of vehicle is a quite practical and applied course, in addition to the experiment and data collection, the analysis and optimization of data is also very important. After the test, students tend to processing data simply, and a simple conclusion, actually a large of data, can be analyzed that what the problems are and how to solve in the handling stability and smoothness test, this is more important. The examination way: students are divided into several groups, each group should complete analysis and optimization of a specified data module, and write research report, at last the examination adopts the way of defense.

\section{B. Learning-outcomes orientation, optimization of comprehensive experimental curriculum}

Due to the lack of clear goal orientation in experiment designing, students think the experiment project is "boring", this would affect the teaching effect of course. The student's learning process tends to a planned and gradual process. According to the "gradualness" characteristics of students in the learning process, the teacher may introduce the OBE education mode into the experimental operation teaching, the experiment teaching can be divided into three stages, to formulate the corresponding learning goal in every stage. According to the goal of each stage, the teacher may use the reverse design principles of OBE mode to design the teaching contents in each stage [4].

Stage 1: experimental basis. In allusion to the demands of experimental teaching, in this stage teachers guide students to review relevant knowledge, namely "review the past", guide students self-learning, to lay a good theoretical basis for subsequent experiments.

Stage 2: validating experiments. In this stage mainly let students learn the basic function of data acquisition, to lay the foundation for subsequent experiments.

Stage 3: designing experiments. The content of this part in the experimental teaching is a relatively difficult link, including the experimental process scheduling, data acquisition, data management, data storage management, etc. For teaching demands, according to the experimental process and scale, teacher can divide the experiment into "will do" and "choose to do", and divide students into groups, each group reports the outcomes of experiment, and gets corresponding evaluation.

\section{Learning-outcomes orientation, establishing diversified and standardized evaluation mode}

The OBE's “outcomes” reflected in the comprehensive experimental course teaching namely is the ability students gained through the curriculum; this ability can be shown as understanding of knowledge, using knowledge to solve practical problems, personal expression, cooperation between the students, etc. The examination by submitting an experimental report is too simple, and difficult to reflect students' learning outcomes. The OBE idea puts the students' ability training as the first priority, so teachers shall examine students' learning effects in diverse ways, focusing on whether the learning outcomes match the expected goal.

\section{CONCLUSIONS}

As a kind of innovation to the traditional education mode, The OBE education idea is of great guiding significance in the optimization of teaching contents, the renewal of teaching means and reasonable setting of evaluation system. By introducing OBE concept into the construction of comprehensive experimental curriculum, this paper has carried out the reform and exploration on the vehicle engineering experimental teaching content, teaching strategies and evaluation mode in somehow, the principles of OBE will be introduced into the construction of interrelated curriculums group in the future, to lay a good foundation for the OBE education mode further playing a guiding role in the teaching. 


\section{ACKNOWLEDGMENT}

Project supported by the Foundation of Shanghai DianJi University (No. B1-0224-16-003-054, No. 16TSXK01 and No. B1-0224-16-005-011).

\section{REFERENCES}

[1] Spady W G, " Outcome-based education: critical issues and answers," Arlington: American Association of School Administrators, pp.1-10 1994.
[2] Willis S, Kissane B. Systemic approaches to articulating and monitoring student outcomes: are they consistent with outcome-based education. Studies in Educational Evaluation, vol.23, pp.5-30, 1997.

[3] Gu Pei-hua, Hu Wen-long, Lin Peng, etc. "outcomes-based" Engineering education modes: practice and exploration of Shantou university. Journal of higher engineering education research, pp.27-37, 1997.

[4] Jiang Bo. OBE: Education on the basis of the outcomes. Journal of foreign education research, vol.30, pp.35-37, 2003. 